treated with anti-streptococcic serum, although when the treatment was commenced the patient appeared to be moribund.

Dr. Thompson afterwards showed three cases of micro-cephalic idiocy.

Dr. MACPHAIL expressed the general opinion of the meeting that it was much indebted to Drs. McConaghey and Thompson for exhibiting such interesting cases.

The Report of the St: tistical Committee was discussed at some length. Dr. Bedpord Pirrce explained several of the recommendations of the Committee, and extracts from a criticism by Dr. Mercier were read. A general approval of the tables proposed in the repgrt was expressed, and the suggested division of the registers into civil and medical also met with the approval of the meeting.

There was, however, a decided expression of opinion that before being adopted by the Association the proposed tables should be submitted to an expert for criticism.

The following resolutions were adopted upon specific points, and the Secretary instructed to send them to the Secretary of the Statistical Committee.

(a) Proposed by Dr. Mrnzies, seconded by Dr. Lragr, and carried nem con.

"That General Table II be expanded, so that the total admissions are subdivided so as to discriminate between direct admissions and transfers, lapsed orders, etc."

(b) Proposed by Dr. Mrnzirs, seconded by Dr. Shrzdon, and carried nem con. "That the term 'First Attack' (vide Admission Group, Table I, p, 13, et seq.) should be defined so that it may be quite clear whether or no uncertified insanity is to be considered an attack of insanity for statistical purposes."

(c) (Table IV. Forms of Insanity.) It was proposed by Dr. Menzins, and seconded by Dr. LeGGr- "That Table IV be referred back to the Committee for further consideration." An amendment, proposed by Dr. MACDOWALL, and seconded by Dr. Hitchcock, was carried by seven to three-" That Table IV be accepted, but that, in the opinion of the Division, the time has come when the Association might with advantage consider the question of the classification of insanity."

(d) Proposed by Dr. Macdowall, and seconded by Dr. Sheldon-"That Table $V$ be accepted if classification of occupations therein satisfies the Commissioners in Lunacy."

(e) (Table VI. Atiological.) There was a decided expression of opinion in favour of the proposed table as a whole. Dr. Mrnzirs proposed, Dr. Shrldon seconded, and it was carried unanimously- "That Subdivisions $c$ (Heredity) and $k$ (Congenital and Infantile Mental Deficiency) should precede all the other causal factors, and be separated from Mental and Physical Stress."

At the conclusion of the meeting Dr. Macdowall proposed, and Dr. Macphail seconded, a hearty vote of thanks to Dr. Sheldon for his hospitality, which was carried by acclamation.

The members afterwards dined at the Midland Hotel, Manchester.

\title{
SOUTH-WESTERN DIVISION.
}

The Autumn Meeting of the South-Western Division was held, by invitation ci Dr. Lionel A. Weatherly (who kindly entertained the members), at Bailbrook House, Bath, on Friday afternoon, October 29th, 1904

Dr. Lionel A. Weatherly was voted to the chair.

Dr. MacDonald said before they proceeded with the business of the day they could not but make reference to what they all felt was a great blank in that room, occasioned by the death of their good friend Dr. Benham, who, as he was quite sure was well known to them all, had been one of the strongest, most active, and most able members and supporters not only of that Division, but of the entire work of the Association. While he was not one who paraded his views or himself very much, yet to those who knew Dr. Benham he was what was something more, a sound and true friend. (Hear, hear.) He felt himself, having known him for 
thirty years-for they were students together at Aberdeen-that he had lost a friend. He desired that the following resolution of their regret be entered on the minutes of the proceedings of the Division:

"That the members of the South-Western Division of the Medico-Psycho-

logical Association desire to express their deep and great regret at the loss

they have so unexpectedly sustained by the sudden death of their valued

friend and member, Dr. H. A. Benham, who, from its initiation, was one of

the truest and warmest supporters of the South-Western Division."

Dr. Avelinr seconded the motion, and associated himself with the expression of deep regret which Dr. MacDonald had uttered. A', one who had worked with him for some years as an assistant medical officer, and who since then had been associated with him as a friend, he felt he could speak of his constant kindness, his generosity, his unswerving loyalty, and fidelity.

Dr. Whitz said, as the immediate past President of the Association, he felt, on an occasion like that, he could not allow the resolution to pass without saying a few words with regard to their late lamented friend, Dr. Benham. They knew how ably he filled the post of Registrar of the Association, the marvellous tact and aptitude of the man, his great administrative capacity, and his sound common sense. Those qualities endeared him to one and all of them.

The ChaIRMan, in putting the resolution, which was carried all upstanding, said Dr. Benham was a very old friend of his own, and he valued him most highly, as they all did.

Nrw Mruber.

Dr. James Alexander Gibb, M.B., Ch.B., A.M.O., of the Dorset County Asylum, was unanimously elected a member.

\section{The Next Merting.}

Dr. MACDonald gave a hearty invitation to the members to hold their meeting on April IIth, 1905, at the home of his labours, Dorchester.

On the motion of Dr. Avering the invitation was cordially accepted.

\section{The Statistical Committez's Report.}

The meeting proceeded to discuss the new tables proposed by the Statistical Committee, table by table.

The following were the alterations suggested, the other tables being passed without amendment :

Table 1.-Dr. MAcDonald moved that a column be added (by the subdivision of column I) showing private patients. Dr. MacBryan seconded, and this was agreed to.

Admission Group Table IV.-On the motion of Dr. MacDonald, seconded by Dr. MAcBryan, it was decided to recommend the deletion of the words "including dementia pracox." It was also resolved to recommend the substitution of "general paralysis of the insane " for " general progressive paralysis."

Residue Group Table II.-The same alterations were made as in the last. mentioned table.

Civil Register.-On the motion of Dr. MacDonald, seconded by Dr. Avreine, * was resolved to delete the column "Criminal (not included in private)," as having no useful purpose.

Register of Discharges and Transfers, and Register of Deaths.-In both these tables it was resolved that the column "Criminal" be deleted.

Dr. Cotron, of the Bristol Prison, then read a paper on "Mental Unsoundness and Mental Disease in a Local Prison" (see page 99).

The members and friends dined afterwards at Fort's Restaurant, Bath. 